\title{
COMPARAÇÃO DE DIETAS ARTIFICIAIS E TIPOS DE MILHO, PARA CRIAÇÃO DE Anagasta kuehniella (ZELLER, 1879) (LEPIDOPTERA: PYRALIDAE) ${ }^{1}$
}

\author{
E.A. MAGRINI ${ }^{2,4}$; J.R.P. PARRA ${ }^{2}$; M.L. HADDAD ${ }^{2}$; PAULO SÉRGIO M. BOTELHO ${ }^{3,4}$ \\ ${ }^{2}$ Departamento de Entomologia-ESALQ/USP, C.P. 9, CEP: 13418-900-Piracicaba,SP \\ ${ }^{3}$ Departamento de Biotecnologia Vegetal-CCA/UFSCar, C.P. 153, CEP: 13600-970-Araras,SP \\ ${ }^{4}$ Bolsista do CNPq/RHAE/ESALQ.
}

\begin{abstract}
RESUMO: O objetivo da pesquisa foi comparar o desenvolvimento biologico de Anagasta kuehniella (Zeller, 1879), visando à produção de Trichogramma, em dietas contendo milho amarelo (híbrido comercial AG-106) em relaçāo à dieta com milho branco, ambas suplementadas com levedura de cerveja. $O$ trabalho foi conduzido a $25 \pm 2^{\circ} \mathrm{C}$, fotofase de 14 horas e UR de $60 \pm 10 \%$. Foram analisados os seguintes parâmetros biológicos: duraçāo e viabilidade do ciclo (ovo-adulto), peso médio de adultos, número médio de ovos, porcentagem de adultos deformados, número médio de ovos por dia e duração e viabilidade dos ovos. Levando-se em consideração os parâmetros estudados, pôdese concluir que a dieta à base de farinha de milho amarelo acrescida de $3 \%$ de levedura pode ser utilizada em criações massais de $\boldsymbol{A}$. kuehniella, por ser de valor nutricional semelhante à dieta de milho branco, e pelo fato de não afetar os parâmetros biológicos observados.
\end{abstract}

Deseritores: Anagasta kuehniella, biologia, dietas artificiais

\section{COMPARISON OF ARTIFICIAL DIETS AND DIFFERENT VARIETIES OF MAIZE, FOR REARING Anagasta kuehniella (ZELLER, 1879) (LEPIDOPTERA: PYRALIDAE)}

\begin{abstract}
ARSTRACT: This work was carried out to compare the development of Anagasta kuehniella (Zeller,1879), for Trichogramma mass rearing production, with an artificial diet consisting of a hybrid commercial yellow maize and yeast, in relation to a diet containing white maize with very high lysine and tryptophan contents, added to yeast. The following parameters were evaluated: life cycle length, adult weights, fecundity, egg laying, adult malformations, and mortality at the different development stages. The laboratory conditions were temperature of $25 \pm 2^{\circ} \mathrm{C}$, photophase of $14 \mathrm{hr}$ and $\mathrm{RH}$ of $60 \pm 10 \%$. Based on these parameters, the diet consisting of commercial maize showed to be nutritionally suitable for $A$. kuehniella rearing and may replace the diet consisting of a very rich maize variety for mass rearing purposes.
\end{abstract}

Key works: Anagasta kuehniella, biology, artificial diets

\section{INTRODUÇÃO}

Existem muitas dietas artificiais que vêm sendo utilizadas para criação de lepidópteros pragas, tendo como uma das fontes protéicas o milho. Este milho, na maioria das vezes, deve ser rico em lisina e triptofano para proporcionar um bom desenvolvimento dos insetos. Assim, para Diatraea saccharalis (Fabr., 1794), os milhos Opaco, Nutrimaiz ou branco, com altos teores daqueles aminoácidos, têm dado bons resultados quando utilizados em dieta artificial para produção de parasitóides larvais (PARRA \& MIHSFELDT, 1992). Na dieta para Anagasta kuehniella (Zeller, 1879), hospedeiro alternativo utilizado para produção massal de Trichogramma, a dieta normalmente é composta de farinha de trigo integral (97\%) e levedura (3\%) (PARRA et al., 1989). MAGRINI et al. (1993) observaram que o milho branco também pode ser utilizado para criação de $A$. kuehniella em substituição à farinha de trigo integral, com algumas vantagens, pela

' Pesquisa financiada pela FBB.

Sci. agric., Piracicaba, 52(1):60-64, jan./abr., 1995 
facilidade de aquisição do milho na região de Piracicaba, e por proporcionarbom desenvolvimento do inseto. Entretanto, nem sempre há disponibilidade deste milho branco para a confecção deste novo meio proposto, em outras regiões do país.

Assim, o objetivo deste trabalho foi comparar o desenvolvimento biológico de Anagasta kuehniella, visando a produção de Trichogramma, em dietas contendo farinha de milho branco ou farinha de milho amarelo, esta obtida de hibrido facilmente encontrado no comércio, ambas suplementadas com levedura de cerveja.

\section{MATERIAL E MÉTODOS}

O trabalho foi desenvolvido no laboratório de Biologia de Insetos do Departamento de Entomologia da Escola Superior de Agricultura "Luiz de Queiróz" (ESALQ), Universidade de São Paulo (USP), à temperatura de $25 \pm 2{ }^{\circ} \mathrm{C}$, fotofase de 14 horas e UR de $60 \pm 10 \%$. Foi comparado o desenvolvimento biológico de Anagasta kuehniella (Zeller, 1879) em 2 dietas com a seguinte composição: 1) Milho amarelo (cultivar AG 106) $(97 \%)+$ levedura de cerveja $(3 \%)$; 2 ) Milho branco $(97 \%)+$ levedura de cerveja (3\%).

Adotou-se a metodologia de PARRA et al. (1989): setenta tiras de papelão corrugado ( 37,5 $\mathrm{cm}$ de comprimento por $2,0 \mathrm{~cm}$ de largura) cortadas com serra circular, foram agrupadas em feixes de tiras justapostas e presas por elástico. Estas foram colocadas no fundo de uma bandeja de polietileno $(40 \times 35 \times 6 \mathrm{~cm})$ ocupando quase totalmente seu espaço. $O$ alimento foi colocado sobre o feixe de tiras, espalhado, para que todos os orifícios fossem preenchidos. Para cada tratamento foi colocado $1,0 \mathrm{~kg}$ de alimento $e$ os ovos, provenientes da criação do Departamento de Entomologia da ESALQ/USP, foram distribuídos sobre a superfície da bandeja, num total de $0,2 \mathrm{~g}$ para cada uma delas (cerca de 7.200 ovos).

Posteriormente, a bandeja foi coberta por um saco de polietileno com abertura central de 20 x $20 \mathrm{~cm}$ (vedado com tecido tipo "filo") para aeração. Cada bandeja constituiu uma parcela, e houve seis repetições por tratamento. Registrou-se a duração e a viabilidade do período ovo-adulto.

Durante o período de emergência, os indivíduos coletados, três vezes por semana, foram mortos com clorofórmio, contados (inclusive os deformados) e pesados. $O$ delineamento experimen- tal utilizado foi inteiramente casualizado com esquema fatorial composto por dois fatores. No início da emergência (primeira fase) e na quinta semana seguinte (segunda fase) foram separados, por tratamento, 20 casais de $A$. kuehniella, para a avaliação da capacidade de postura, através de observações diárias (STEIN \& PARRA, 1987). Neste caso, três fatores foram considerados no esquema fatorial.

Em ambas as fases, foram separados 200 ovos da primeira postura, por tratamento. Esses ovos, em grupos de 50, foram colocados sobre papel de filtro e este sobre farinha de milho, que teve por finalidade atrair as lagartas recém eclodidas de A. kuehniella para alimentação. Evitou-se assim o canibalismo comum na espécie (SCHMIDT, 1991).

Todo esse conjunto, acondicionado em placa de Petri, foi vedado com fita adesiva e colocado em câmara climatizada a $25 \pm 1^{\circ} \mathrm{C}$, fotofase de 14 horas e UR de $60 \pm 10 \%$. Cinco dias após, as placas foram abertas e os ovos examinados em microscópio estereoscópico, contando-se os inviáveis. Calculou-se, posteriormente, a viabilidade por tratamento, em ambas as fases.

Os dados obtidos foram submetidos à análise de variância e as médias comparadas pelo teste de Tukey, ao nível de $5 \%$ de probabilidade.

\section{RESULTADOS E DISCUSSÃo}

A duração média do período ovo-adulto de Anagasta kuehniella (Zeller, 1879) foi de 50,82 e 51,05 dias, respectivamente, para as dietas de milho amarelo e branco (TABELA 1). Esses resultados são próximos aos obtidos por MAGRINI et al. (1993) que encontraram o valor de 52,80 dias para uma dieta à base de milho branco $(97 \%)$ mais levedura de cerveja (3\%).

A viabilidade do período ovo-adulto de $A$. kuehniella variou de $60,64 \%$, na dieta de milho amarelo, a $58,34 \%$, na dieta de milho branco (TABELA 1). Esses valores são altos se comparados aos obtidos por PARRA et al. (1989) e MAGRINI et al. (1993), pois estes últimos autores obtiveram somente $22,73 \%$ de viabilidade, quando trabalharam em condições semelhantes, com dieta à base de milho branco $(97 \%)$ mais levedura de cerveja (3\%). As únicas razões que podem justificar tais diferenças são o genótipo e procedência dos milhos utilizados, desde que a metodologia adotada foi semelhante em todos os experimentos. 
TABELA 1. Duracão e viabilidade do período ovo-adulto de $A$. kuehniella e porcentagem de adultos deformados em duas dietas com dois tipos de milho. Temperatura: $25 \pm 22^{\circ} \mathrm{C}$; fotofase: 14 horas; UR: $60 \pm 10 \%$.

\begin{tabular}{llll}
\hline \multicolumn{1}{c}{ Dieta } & $\begin{array}{l}\text { Duração } \\
\text { (dias) }\end{array}$ & $\begin{array}{l}\text { Viabilidade } \\
(\%)\end{array}$ & $\begin{array}{l}\text { Adultos } \\
\text { deformados (\%) }\end{array}$ \\
\hline $\begin{array}{l}\text { Farinha de milho amarelo(97\%) } \\
\text { + levedura de cerveja(3\%) }\end{array}$ & $50,82 \pm 0,82 \mathrm{a}$ & $60,64 \pm 7,20 \mathrm{a}$ & $3,20 \pm 0,14$ \\
$\begin{array}{l}\text { Farinha de milho branco(97\%) } \\
\text { + levedura de cerveja (3\%) }\end{array}$ & $51,05 \pm 0,66 \mathrm{a}$ & $58,34 \pm 2,34 \mathrm{a}$ & $4,99 \pm 0,17$ \\
\hline $\begin{array}{l}\text { F(dieta) } \\
\mathrm{CV}(\%)\end{array}$ & $0.0635^{\mathrm{na}}$ & $0.1287^{\text {ns }}$ & \\
\hline
\end{tabular}

Médias seguidas de mesma letra não diferem entre si, pelo teste de Tukey, ao nível de $5 \%$ de probabilidade. ns: não-significativo ao nível de $5 \%$ de probabilidade.

Observou-se que mais de $97 \%$ dos indivíduos emergiram até a quarta semana em ambas as dietas (Figura 1), resultados superiores aos obtidos por MAGRINI et al. (1993) que obtiveram, $85 \%$ de emergência nesse mesmo período. De forma análoga ao observado por esses autores a porcentagem de adultos deformados foi desprezível, não devendo, portanto, este parâmetro ser usado como critério para selecionar a melhor dieta para A. kuehniella (TABELA 1).

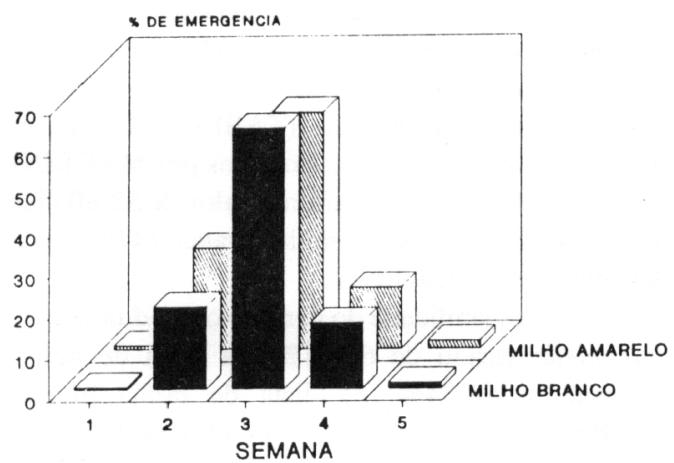

Figura 1. Emergência semanal de A. kuehniella em duas dietas com dois tipos de milho. Temperatura: $25 \pm 2^{\circ} \mathrm{C}$; Fotofase: 14 horas; UR: $60 \pm 10 \%$.

Quanto ao peso, não houve diferença estatística entre adultos provenientes das duas fases (TABELA 2), embora com tendência de serem mais pesados insetos emergidos na primeira semana (Figura 2), como já observado por PARRA et al. (1989) e MAGRINI et al. (1993).

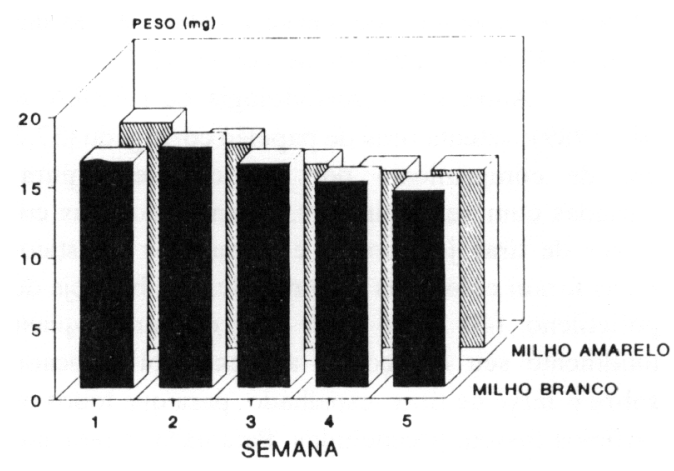

Figura 2. Peso médio ( $\mathrm{mg}$ ) de adultos de $A$. kuehniella, obtidos por semana nas duas dietas com dois tipos de milho.Temperatura: $25 \pm 2^{\circ} \mathrm{C}$; Fotofase: 14 horas; UR: $60 \pm 10 \%$.

O número médio de ovos por fêmea foi maior na primeira fase ( $1^{\mathrm{a}}$ semana) em ambas as dietas, o que confirma o relato de PARRA el al., (1989) de que geralmente adultos mais pesados produzem mais ovos; na comparação entre dietas, as fêmeas provenientes da dieta de milho amarelo puseram maior número de ovos (TABELA 2). 
TABELA 2. Peso médio de adultos de $A$. kuehniella e respectivo número de ovos postos nas fases 1 ( $1^{\mathrm{a}}$ semana) e $2\left(5^{a}\right.$ semana) em duas dietas artificiais. Temperatura: $25 \pm 2^{\circ} \mathrm{C}$; Fotofase: 14 horas; UR: $60 \pm 10 \%$.

\begin{tabular}{|c|c|c|c|c|c|c|}
\hline \multirow[t]{2}{*}{ Dieta } & \multicolumn{3}{|c|}{ Peso (mg) } & \multicolumn{3}{|c|}{$\mathrm{N}^{0}$ de ovos/ $/ 9$} \\
\hline & Fase 1 & Fase 2 & Média & Fase 1 & Fase 2 & Média \\
\hline $\begin{array}{l}\text { Farinha de milho } \\
\text { amarelo }(97 \%)+ \\
\text { levedura de } \\
\text { cerveja }(3 \%)\end{array}$ & $15,70 \mathrm{aA}$ & $13,66 \mathrm{aA}$ & 14,43 & $279,30 \mathrm{aA}$ & $184,70 \mathrm{aB}$ & 235,30 \\
\hline $\begin{array}{l}\text { Farinha milho } \\
\text { branco }(97 \%)+ \\
\text { levedura de } \\
\text { cerveja }(3 \%)\end{array}$ & $16,07 \mathrm{aA}$ & $14,90 \mathrm{aA}$ & 16,00 & $239,48 \mathrm{bA}$ & $181,54 \mathrm{bB}$ & 211,83 \\
\hline $\mathrm{F}$ (dieta $*$ fase) & $0.6137^{\mathrm{ns}}$ & & & $23489,8 \cdots$ & & \\
\hline
\end{tabular}

* : Médias seguidas da mesma letra minúscula na coluna e maiúscula na linha não diferem entre si, pelo teste de Tukey, ao nível de $5 \%$ de probabilidade.

ns: não significativo

**: significativo ao nível de $1 \%$ de probabilidade

O número de ovos por fêmea, em ambas as dietas, foi superior àquele obtida por MAGRINI et al. (1993), sendo, entretanto, menor do que o relatado por PARRA et al. (1989) na dieta de farinha de trigo integral e levedura, provavelmente devido à maior riqueza nutricional deste meio.

Tanto para a primeira como para a $2^{a}$ fase (Figuras 3A e 3B) houve uma concentração de postura de $A$. kuehniella, independente da dieta, nos primeiros dias de vida, fato desejável num processo de criação massal (MAGRINI et al., 1993).

Em termos médios, a porcentagem de fêmeas que não realizou postura foi semelhante nas duas dietas, aumentando visivelmente o número de indivíduos que pôs menos de 100 ovos (critério determinado em pesquisas anteriores) na $2^{a}$ fase, especialmente na dieta de milho branco, com um número 2,3 vezes maior do que o das fêmeas provenientes da dieta de milho amarelo (TABELA 3).

A viabilidade dos ovos foi superior a 90\% nas duas dietas, para ambas as fases, com exceção da fase 1, na dieta de milho branco, onde se obteve $66 \%$; em geral, não foi observada influência do alimento sobre esse parâmetro. $O$ período embrionário também não foi afetado, ficando próximo de 4 dias nas duas dietas e fases estudadas.
TABELA 3. Porcentagem de fêmeas de $A$. kuehniella que não realizaram postura ou que puseram menos de 100 ovos, na primeira (fase 1) e na quinta (fase 2) semanas. Temperatura: $25 \pm 2^{\circ} \mathrm{C}$; fotofase: 14 horas; UR: $60 \pm 10 \%$.

\begin{tabular}{|c|c|c|c|c|}
\hline \multirow[t]{2}{*}{ Dieta } & \multicolumn{2}{|c|}{ Fase 1} & \multicolumn{2}{|c|}{ Fase 2} \\
\hline & I & II & I & II \\
\hline
\end{tabular}

Farinha de milho amarelo $(97 \%)+4,00 \quad 8,00 \quad 4,00 \quad 20,00$ levedura de cerveja (3\%)

Farinha de milho branco $(97 \%)+\quad 0,00 \quad 8,00 \quad 8,33 \quad 45,83$ levedura de cerveja (3\%)

(I) \% de fêmeas que não realizaram postura (II) \% de fêmeas que puseram menos de 100 ovos

Assim, através das comparações do desenvolvimento biológico de $A$. kuehniella, nas duas dietas estudadas, pôde-se verificar que a dieta de 
milho amarelo teve o mesmo valor nutricional que o milho branco para esta traça, criada por uma geração em laboratório, e pode ser utilizada para criações massais deste inseto como hospedeiro alternativo para produção de Trichogramma. É conveniente salientar contudo que embora no trabalho de MAGRINI et al. (1993), o número de ovos posto por fêmea na dieta de farinha de trigo integral e levedura tenha sido semelhante àquele obtido na dieta de milho branco e levedura, PARRA et al. (1989) obtiveram um número de ovos bastante maior na primeira dieta. Assim, é necessário que sejam realizadas novas pesquisas para verificar se, por gerações sucessivas, a dieta
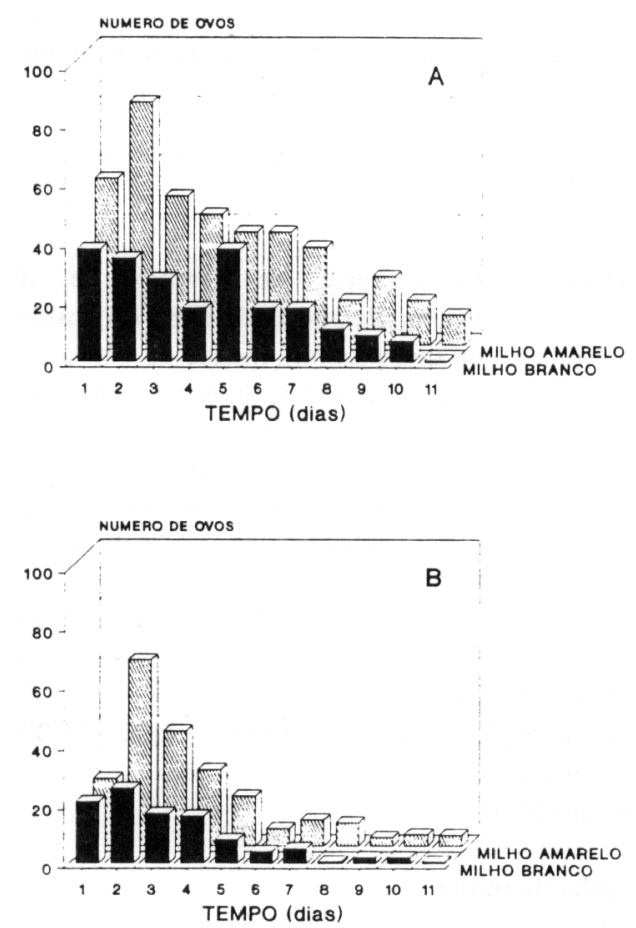

Figura 3. Número médio de ovos de $A$. kuehniella, posto diariamente por fêmeas provenientes das duas dietas nas fases 1 (A) (1 ${ }^{\text {a }}$ semana) e 2 (B) ( $5^{\text {a }}$ semana). Temperatura: $25 \pm 2^{\circ} \mathrm{C}$; Fotofase: 14 horas; UR: $60 \pm 10 \%$. de milho acarretará ou não decréscimo na produção de ovos para criação de Trichogramma spp., em relação à dieta convencional de farinha de trigo integral e levedura.

\section{CONCLUSÃO}

A dieta artificial, à base de milho amarelo, é adequada nutricionalmente para criação de Anagasta kuehniella (Zeller, 1879), visando a produção de Trichogramma spp.

\section{REFERÊNCIAS BIBLIOGRÁFICAS}

MAGRINI, E.A.; BOTELHO, P.S.M.; PARRA, J.R.P.; HADDAD, M.L. Comparaçāo de dietas artificiais para criacão massal de Anagasta kuehniella (Zeller, 1879) (Lepidoptera: Pyralidae). Anais da Sociedade Entomologica do Brasil, Londrina, v.22, n.2, p.361$371,1993$.

PARRA, J.R.P.; LOPES, J.R.S.; SERRA, H.J.P.; SALES JÚNIOR, O. Metodologia de criaçāo de Anagasta kuehniella (Zeller, 1879) para produção massal de Trichogramma spp. Anais da Sociedade Entomológica do Brasil, Jaboticabal, v.18, n.2, p.403-415, 1989 .

PARRA, J.R.P; MIHSFELDT, L.H. Comparison of artificial diets for rearing Diatraea saccharalis. In: ANDERSON, T.E; LEPPLA, N.C., eds. Advances in insect rearing for research and pest management. Boulder, Westview Press, 1992. p. 195-210.

RODRIGUES FILHO, I.L.; HADDAD, M.L.; PARRA, J.R.P.; STEIN, C.P. Comparação de dietas úmida e seca para criação de Anagasta kuehniella (Zeller, 1879). Anais da Sociedade Entomológico do Brasil, Jaboticabal, v.20, n.2, p.417-425, 1991 .

SCHMIDT, F.G.V. Armazenamento, em baixas temperaturas, de ovos de Anagasta kuehniella (Zeller, 1879) e de Corcyra cephalonica (Stainton, 1865), visando a produção de Trichogramma spp. Piracicaba, 1991. 108p. Dissertação (Mestrado) - Escola Superior de Agricultura "Luiz de Queiroz", Universidade de São Paulo.

STEIN, C.P.; PARRA, J.R.P. Aspectos biológicos de Anagasta kuehniella (Zeller, 1879) criada em 2 substratos alimentares. Anais da Sociedade Entomologica do Brasil, Jaboticabal, v.16, n.1, p.173-185, 1987.

Entregue para publicação em 03.05.94

Aceito para publicação em 20.09.94 